\title{
Structural characterization of a variety of spider silks from Turkey using different biophysical techniques
}

\author{
Semra İde ${ }^{\mathrm{a}, *}$, Sevgi Haman Bayarı ${ }^{\mathrm{b}}$, Tuncay Türkeş ${ }^{\mathrm{c}}$, Y. Orhan Mergen ${ }^{\mathrm{d}}$, Ömer Çelik ${ }^{\mathrm{e}}$, \\ Vural Bütün ${ }^{\mathrm{f}}$, Mustafa F. Sargon ${ }^{\mathrm{g}}$, Neslihan Kocatepe ${ }^{\mathrm{d}}$ and Manfred Kriechbaum ${ }^{\mathrm{h}}$ \\ ${ }^{a}$ Faculty of Engineering, Department of Physics Eng., Hacettepe University, Beytepe, Ankara, Turkey \\ ${ }^{\mathrm{b}}$ Faculty of Education, Department of Physics, Hacettepe University, Beytepe, Ankara, Turkey \\ ${ }^{\mathrm{c}}$ Faculty of Science, Department of Biology, Niğde University, Niğde, Turkey \\ ${ }^{\mathrm{d}}$ Faculty of Science, Department of Biology, Hacettepe University, Beytepe, Ankara, Turkey \\ ${ }^{\mathrm{e}}$ Faculty of Science and Art, Department of Physics, Harran University, Sanliurfa, Turkey \\ ${ }^{\mathrm{f}}$ Faculty of Art and Science, Department of Chemistry, Eskişehir Osmangazi University, Meşelik, \\ Eskisehir, Turkey \\ ${ }^{\mathrm{g}}$ Medicine Faculty, Department of Anatomy, Hacettepe University, Sihhiye, Ankara, Turkey \\ ${ }^{\mathrm{h}}$ Institute of Biophysics and Nanosystem Research, Austrian Academy of Sciences, Graz, Austria
}

\begin{abstract}
Various experimental methods (XRD, FTIR, SAXS, DLS and SEM) were used to investigate structures of the silk samples weaved by spiders in Turkey. Silk samples were collected from the natural habitats belonging to the spider species (i.e., Near Salt Lake/Şereflikoçhisar, İvriz Dam/Ereğli-Konya, Karataş Lake/Burdur and several locations in Black Sea Region of Turkey). Among all collected species, Araneidae (Araneus angulatus, Argiope bruennichi, Argiope lobata, Larinoides cornutus), Eresidae (Eresus cinnaberinus), Agelenidae (Agelena labyrinthica), Oecobidae (Uroctea durandi), Miturgidae (Cheiracanthium erraticum), Salticidae (Heliophanus flavipes, Philaeus chrysops), Theridiidae (Steatoda paykulliana) and Gnaphosidae were found significant amongst other spider species. Structural differences and similarities of these species were reported. Diameter range of draglines, inter crystallite distance of nano-size structures, mean size range of nano-structure aggregations, crystallite size range, information about protein content were obtained. The mechanical properties of some silk fibers were also investigated.
\end{abstract}

Keywords: Spider silk, XRD, FTIR, scattering methods, SEM, mechanical testing

\section{Introduction}

Silk is a characteristic product of the spiders. Seven types of silks can be produced by spiders for different purposes such as hiding, feeding, resting, protecting eggs, etc. using their seven different types of glands. It is accepted that, spider silk fibers have the highest tensile strength among all known types of natural fibers. This tensile strength, combined with the high grade elasticity of silk, is utilized remarkably by the spiders. Even though all kinds of spider silk include protein, chemical content and physical

\footnotetext{
*Corresponding author: Prof. Semra İde, Faculty of Engineering, Department of Physics Eng., Hacettepe University, 06800 Beytepe, Ankara, Turkey. Tel.: +90 312297 7248; Fax: +90 312299 2037; E-mail: side@ hacettepe.edu.tr.
} 
properties of silk indicate rich diversity and variance [22]. They are of utmost importance in terms of technological applications because of their exceptional idiosyncrasies (high strength, flexibility, nontoxic, capability to draw water, high protein content, etc.). The superior features of spider silks may be explained by examining their molecular, nano- and micro-size structures. Especially nano-size aggregations such as alanine rich prismatic and glycine-rich planar forms are considerably vital to clarify the strength and flexibility. While silk samples having more (crystalline) alanine rich forms indicate more strength properties, high flexibility stems from the glycine-rich aggregations. This biopolymer fiber is an excellent composition of proteins, crystallites and amorphous polymers $[10,14,41]$.

The scientific literature related to the structural analysis of spider silks weaved by different species has widely increased in the last decade $[10,14,22,41]$. Spider silks are a source of macromolecular structures and constructed by large proteins (fibroins) and the sequence of these proteins depends on the variety of species at most times. Macro size structural analysis may be conducted via DNA translations and a few peptide analyses $[12,16,44]$.

X-ray diffraction and NMR studies show the crystalline regions to consist of pleated beta-sheets of polyalanine $[29,37,40]$ and the predominant secondary structure of the amorphous matrix (causing more elasticity) is the glycine-rich 31-helix [40].

DLS (dynamic light scattering) and SAXS (small angle X-ray scattering) methods are useful to know more about nano-aggregations, present in silk structure $[13,19,32,45]$. Natural silk forms and their solutions may be analyzed by using these complementary experimental methods.

Molecular structures were also investigated by IR and Raman spectroscopy [2,35,38]. Mechanical measurement systems have been widely used to investigate mechanical properties such as strength and flexibility [30,39].

Following the utilization of complementary experimental methods, we may obtain valuable knowledge about excellent biomaterials in question. Main aim of this examination is to determine Turkish originated valuable species which are productive, having long life span and surviving capability under laboratory conditions and indicate high mechanical properties.

\section{Materials and methods}

\subsection{Silk sampling}

We periodically collected samples between April and November from plant leaves and stems, ruins, caves, soil cracks, underside of the stones, rocks and dry barks by using the pooter in the Black Sea and Central Anatolia Regions of Turkey. They were then either stored in $70 \%$ ethanol at room temperature. Each dead spider was moved from tubes to jars, which have their labels and which are filled with the solution of 70\% ethanol, with 3-4 drops of glycerin. The identifications were carried out by means of a Nicon SMZ-U stereomicroscope. The keys given by $[15,23,24,34]$ were used for the identification. The specimens were deposited in Archeology Museum of Nigde University (NUAM). Furthermore, the photos of the cobwebs of each spider and the research fields were taken, the GPS data of sampling areas and information with regards to habitat were recorded, and the cocoons of each spider with its cobweb was taken to the laboratory for investigation.

All samples were grouped according to the species and silk types [33]. With the help of their macroscopic images; clean, strong and sufficient amount of samples have been selected.

Araneidae (Simon, 1895), Gnaphosidae (Pocock, 1898), Eresidae (Pocock, 1998) and Agelenidae (Roewer, 1954) familia. Araneus angulatus (Clerck, 1757), Argiope bruennichi (Scopoli, 1772), Argiope 


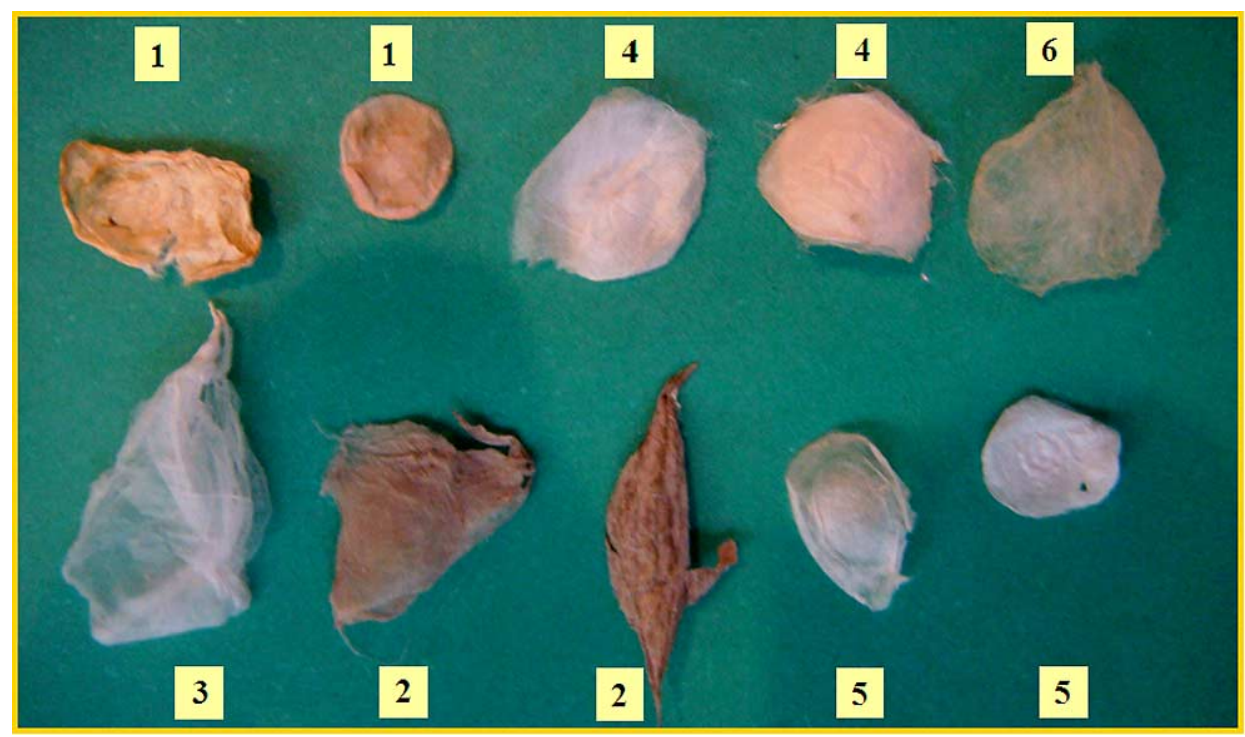

Fig. 1. Cocoon samples (1-Argiope lobata, 2 -Araneus angulatus, 3 - Uroctea durandi, 4 -Xysticus robustus, 5 -Zelotes electus, 6 - Eresus cinnaberinus). (Colors are visible in the online version of the article; http://dx.doi.org/10.3233/SPE-2011-0495.)

lobata (Pallas, 1772), Eresus cinnaberinus, Agelena labyrinthica (Clerk, 1757) and Uroctea durandi (Latreille, 1809) samples were obtained as valuable species for physicists and biologists.

Beside the collection of silk samples from spider's natural habitats; cabins for survival were also prepared for the collected spiders and silk samples that were weaved afterwards, were also collected under laboratory conditions. First, macroscopic observations indicating the color and shape differences among cocoon samples (Fig. 1) and hiding silks were very discernable. The colors of hiding silks of Agelena labyrinthica and Eresus cinnaberinus were white and pink, respectively. Parallel weaved easily countered (under usual Lab. microscope) silk forms (weaved by Agelena labyrinthica) and sticky and massive fabric silk forms (weaved by Eresus cinnaberinus) were also very interesting.

SEM imaging: the samples were mounted on metal stubs with a double-sided adhesive band for SEM analysis. Then, they were sputtered with a 100 Angstrom thick layer of gold in a BIO-RAD Sputter Apparatus (London, UK). The electron micrographs of the specimens (Fig. 2) were taken by a JEOLSEM ASID 10 scanning electron microscope (Tokyo, Japan) at an acceleration voltage of $60 \mathrm{kV}$.

$X$-ray diffraction patterns of the selected samples were recorded on Rigaku Ultima III XRD system $\left(2 \theta: 5-70^{\circ}, \lambda\left(\mathrm{CuK}_{\alpha}\right)\right)$. According to the known crystal and crystalline aggregations located in the biochemical content of the silks, some important peaks in the patterns were investigated by using CELREF program [20].

At first phase, crystallite sizes were determined using Scherer formula by choosing a convenient peak for each pattern (crystallite size $L$ can be computed from the peaks (the full width at half-maximum $\left.\beta_{\mathrm{hkl}}\right)$ by the well-known equation of $L_{\mathrm{hkl}}=k \lambda /\left(\beta_{\mathrm{hkl}} \cos \theta_{\mathrm{hkl}}\right), k$ factor is related with the shape of the crystallite ( 0.89 for spherical, 0.94 for cubic crystallite shape) while $\lambda$ is used for X-ray wave length).

Because each diffraction pattern is composed of two phases (known as amorphous and crystallite structures), the hump related with the amorphous phase was separated from the diffraction peaks in the recorded patterns. So, the convenient peak among others was tried to be chosen for determination of the crystallite size. Following this step, some peaks related with interplanar distances of crystalline phases of alanine, glycine, silk peptide and silk fibroin were indicated as observed peaks in the patterns. 


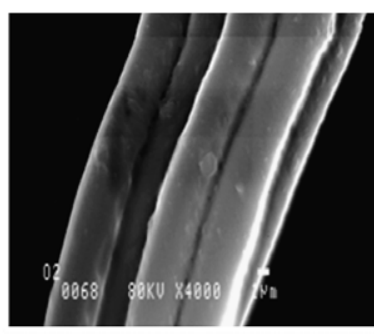

A) Dragline of Argiope bruennichi

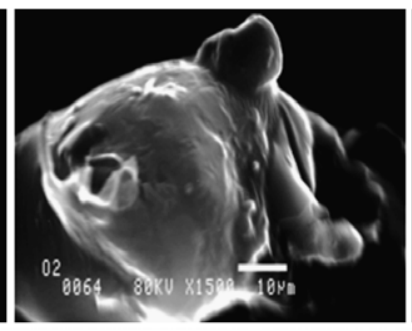

B) Egg cocoon Agelenan Labyrinthica

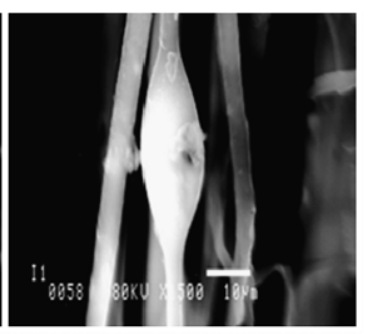

C) Dragline Areneus diadematus
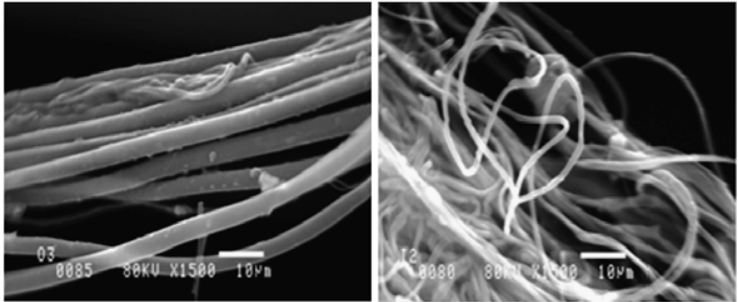

D) Dragline of Pholcus phalangioides

E) Egg cocoon Agelenan Labyrinthica

Fig. 2. SEM images of the representative samples.

Table 1

The widely expected crystalline structures in the content of the silk samples and observed peaks (in the hiding silk of Eresus cinnaberinus) related with these structures

\begin{tabular}{|c|c|c|c|c|}
\hline & Alanine $[31,36]$ & Glycine $[31,36]$ & Silk peptide [5] & Silk fibroin $[1,42]$ \\
\hline Formula & $\mathrm{C}_{3} \mathrm{H}_{7} \mathrm{NO}_{2}$ & $\mathrm{C}_{2} \mathrm{H}_{5} \mathrm{NO}_{2}$ & $\begin{array}{l}\text { (E)5(GDVGGAGAGAT } \\
\text { GGS)2(E)5 }\end{array}$ & $\begin{array}{l}\text { Crystalline phase of alanine, } \\
\text { glycine and serine }\end{array}$ \\
\hline Crystal system & Orthorhombic & Monoclinic & Orthorhombic & Orthorhombic \\
\hline Space group & $\mathrm{P} 2{ }_{1} 2_{1} 2_{1}$ & $\mathrm{P} 2_{1}$ & $\mathrm{P} 2{ }_{1} 2_{1} 2_{1}$ & $\mathrm{P} 2{ }_{1} 2_{1} 2$ \\
\hline Unit cell parameters & $\begin{array}{l}a=6.032 \AA \\
b=12.343 \AA \\
c=5.784 \AA\end{array}$ & $\begin{array}{l}a=7.364 \AA \\
b=4.8703 \AA, \\
c=8.494 \AA, \\
\beta=98.56^{\circ}\end{array}$ & $\begin{array}{l}a=9.91 \AA, \\
b=5.57 \AA, \\
c=20.40 \AA\end{array}$ & $\begin{array}{l}a=9.29 \AA, \\
b=9.44 \AA, \\
c=6.95 \AA\end{array}$ \\
\hline Observed and & $(031)(040)(042)$ & $(110)(200)(120)$ & $(203)(210)(211)(204)$ & $(210)(211)(102)$ \\
\hline recordable peaks & & $(022)(014)$ & $(212)(015)(213)$ & (112) (402) (412) \\
\hline
\end{tabular}

Crystallographic planes related with widely expected crystalline structures in the content of the silk samples and observed peaks in the hiding silk of Eresus cinnaberinus were given in the Table 1. Some of the XRD patterns are given in Fig. 3.

FTIR spectra of spider silks were recorded by using a Perkin-Elmer Spectrum One FTIR Spectrometer. For each sample, 128 interferograms were recorded, averaged and Fourier-transformed to produce a spectrum with a nominal resolution of $4 \mathrm{~cm}^{-1}$. A background spectrum was recorded with a pellet based on pure $\mathrm{KBr}$. The fibres are cut into small pieces, blended with $\mathrm{KBr}$ and pressed into a pellet.

SAXS measurements of the selected samples were performed with the Hecus System3 SAXS camera (Hecus X-ray Systems GmbH, Graz, Austria). The compact system is based upon a combination of a microfocus X-ray beam delivery system (GeniX from Xenocs, Grenoble, France) with Hecus System3 architecture and with $2 \mathrm{D}$ or $1 \mathrm{D}$-SAXS-detector. A resolution of $d \approx 2000 \AA$ with monochromatized 


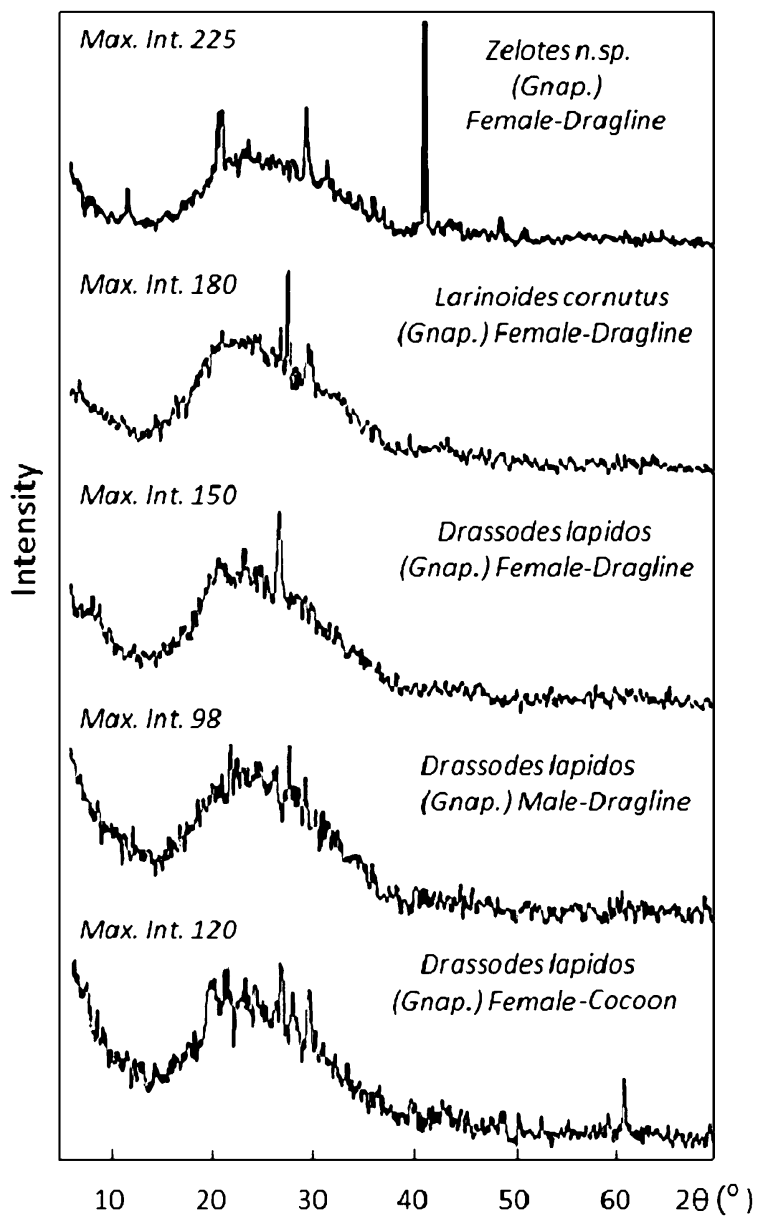

Fig. 3. XRD patterns of three dragline samples (different species) and three silk samples (different forms weaved by the same species) of Gnaphosidae familia.

$\operatorname{CuK}_{\alpha}(\lambda=1.54 \AA)$ with tube current and voltage of $1 \mathrm{~mA}$ and $50 \mathrm{kV}$ can be reached. Exposure time was $700 \mathrm{~s}$ for each curve. The selected SAXS patterns (circles) of the some samples and graphics of fitted functions (continuous line) can be seen together in Fig. 4. Points regarding fitting procedure and $K, l_{\mathrm{c}}$ symbols were illuminated in the result and discussion part.

ALV $\backslash$ CGS 3 Compact Goniometer was used for the dynamic and static light scattering measurements. Spider silks in gel form were prepared by using 1,1,1,3,3,3-hexafluoro-2-propanol as solvent. It takes approximately 5-10 days to obtain gel form out of silk samples. Soluble samples were used in DLS measurements. DLS peaks can be seen in the Fig. 5.

Mechanical tests: filaments, with a length of $55 \mathrm{~mm}$ and a cross-sectional diameter of 275-317 $\mu \mathrm{m}$, were prepared by using approximately 400 draglines from each sample. Micro-scale mechanical testing system of Zwick/Z010 was used to compare strength and strain of selected samples [31] through mechanical testing. Leica DFC $320(\times 50, \times 100)$ was used to measure the diameter of filaments. Strain and stress values of the samples indicate extensibility and tensile strength of the samples, respectively. Mechanical test results are given in Table 2 and Fig. 6. 

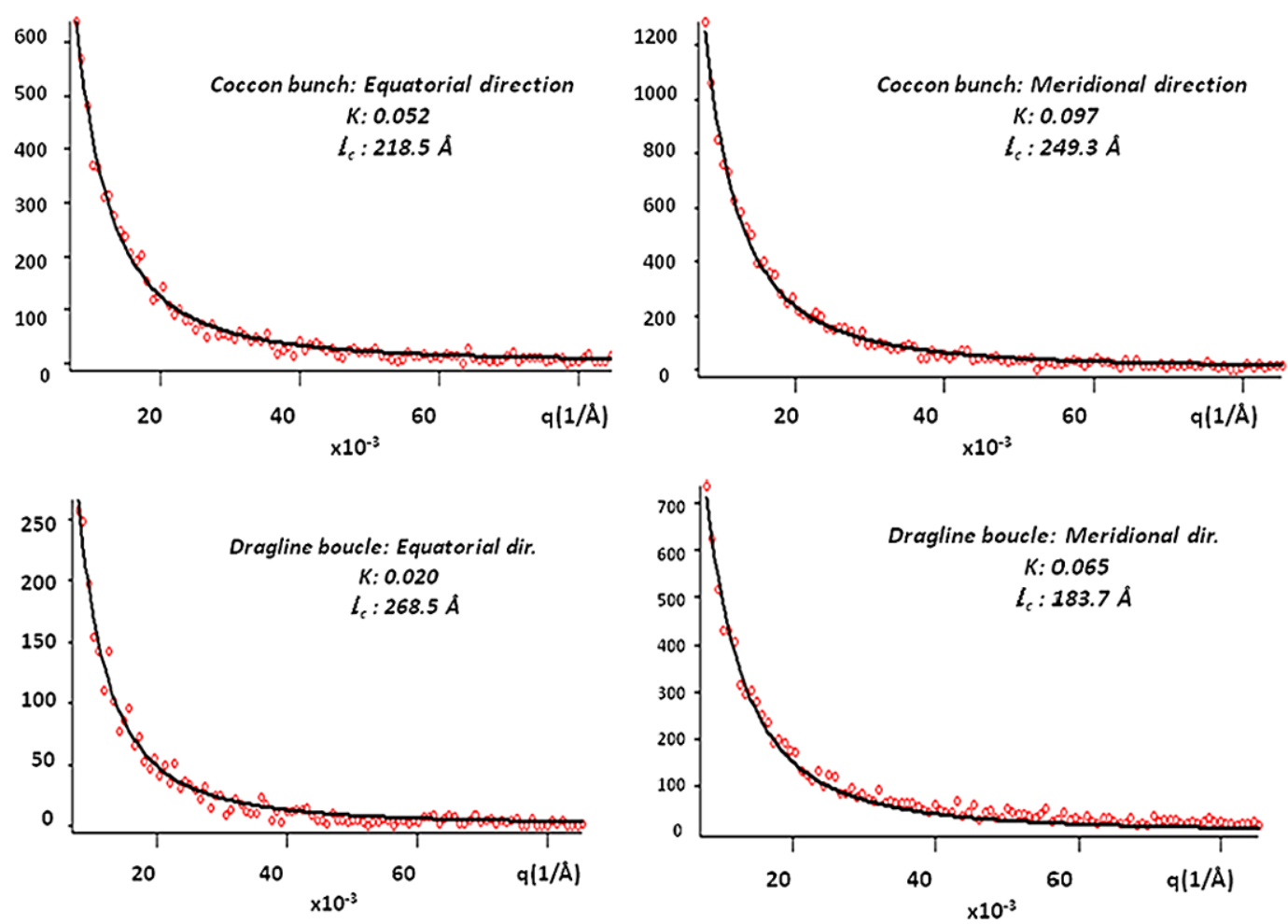

Fig. 4. SAXS patterns of the cocoon and dragline samples (along equatorial and meridional directions) weaved by Argiope lobata. (Colors are visible in the online version of the article; http://dx.doi.org/10.3233/SPE-2011-0495.)

\section{Results and discussion}

\subsection{SEM analysis}

The measured diameter range of cocoon silk fibers and draglines are determined as $0.5-2.3$ and $4.2-$ $15.6 \mu \mathrm{m}$, respectively. Clumps of maximum size of $(90 \mu \mathrm{m})$ and two dimensional silk fiber forms were also detected (Fig. 7).

These two dimensional forms may be aggregated by only the sericin coating part of the silk filament. Only in this case, it may initially cause cylindrical and secondary planar (ribbon) shaped aggregation. In a previous study [31] ribbon shaped (without inner part) sericin coating of fiber structure was also observed within the fracture surface of $B$. Mori silk. Different aggregations around silk fibers were also registered as seen in Fig. 7. These SEM views may help to comprehend the weaving process of the silks.

\subsection{X-ray diffraction analysis}

X-ray diffraction patterns regarding some of the selected samples are shown in Fig. 3. Quantitative changes in the diffraction patterns indicate that they do not only represent different crystallite size (structure factor), but also different amino-acid composition (form factor). The natural dragline samples have broad X-ray diffraction peaks at $2 \theta=10-35^{\circ}$. These sharp peaks in X-ray diffraction patterns $[19,29$, $36,37,40]$ show that the ordered phase of silk has an anti-parallel $\beta$-sheet structure. Spacing between the sheets complies with that of $\beta$-polyalanine, suggesting that the crystallites contain primarily alanine. 

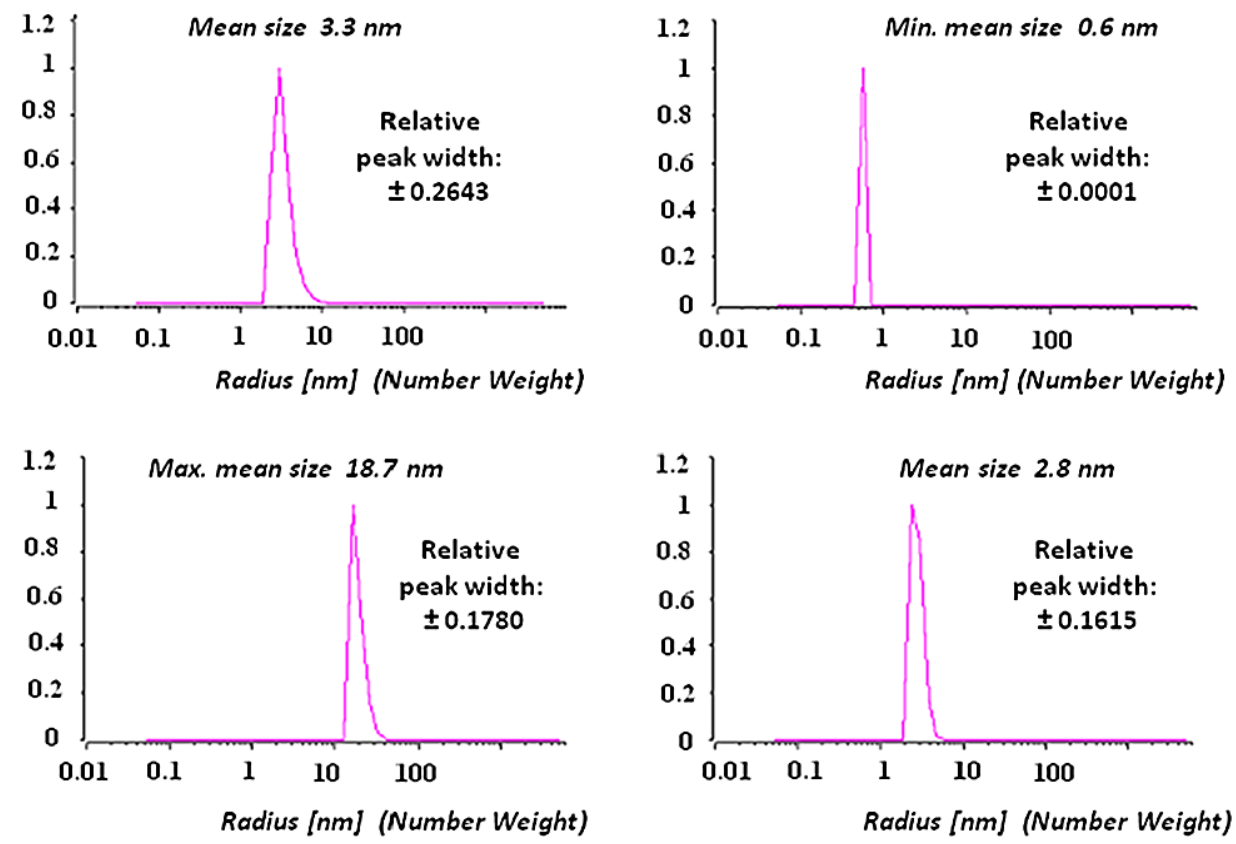

Fig. 5. DLS patterns of the silk samples weaved by Araneus angulatus (mean size 3.3. nm), Zelotes $\mathrm{n}$. sp. (mean size $0.6 \mathrm{~nm}$ ), Argiope lobata (mean size $18.7 \mathrm{~nm}$ ), Uroctea durandi (mean size 2.8). (Colors are visible in the online version of the article; http://dx.doi.org/10.3233/SPE-2011-0495.)

Table 2

Strain and stress values of the silk filaments and a suture

\begin{tabular}{lcc}
\hline The chosen samples and their codes & Ultimate tensile strain & Maximum stress $\left(\mathrm{N} / \mathrm{mm}^{2}\right)$ \\
\hline Eresus cinnaberinus (weaved in the lab.) 1MT1 & 11.81 & 244.97 \\
Araneus angulatus 2MT1 & 8.06 & 287.82 \\
Argiope lobata 3MT1 & 7.08 & 239.63 \\
Eresus cinnaberinus (weaved in natural habitat) 1MT2 & 6.73 & 139.02 \\
Zoletes n. sp. 1 4MT1 & 3.95 & 122.93 \\
Suture (W9940 Ethicon coated polyglactin 910) & 9.28 & 3010.93 \\
\hline
\end{tabular}

The polyalanine regions constitute $\beta$-sheet crystals in an amorphous matrix according to a semicrystalline model of spider dragline silk [16]. A characteristic feature of dragline silk proteins is highly repetitive primary structure with alanine- and glycine-rich motifs (Table 1). These distinct regions contribute to the molecular structure of the spider silk thread. It is suggested that the poly(alanine) patches adopt $\beta$-sheet structures and form crystalline-like particles, which provide strength for the thread.

The results of the present XRD studies are summarized as follows:

(i) Range of crystallite size is $24-89 \AA$ as for the studied samples.

(ii) Cocoon samples indicate high crystallinity in respect to the other silk forms (in bouclet forms in similar sizes).

(iii) Alanine (beta-sheet) peaks are typical and potent in terms of XRD patterns. High alanine peaks indicating big tensile strength. Female dragline has bigger tensile strength than that of male dragline for Drassodes lapidosus species. Cocoons of the same species are also indicating big tensile strength due to their high protein content and high crystallinity. 


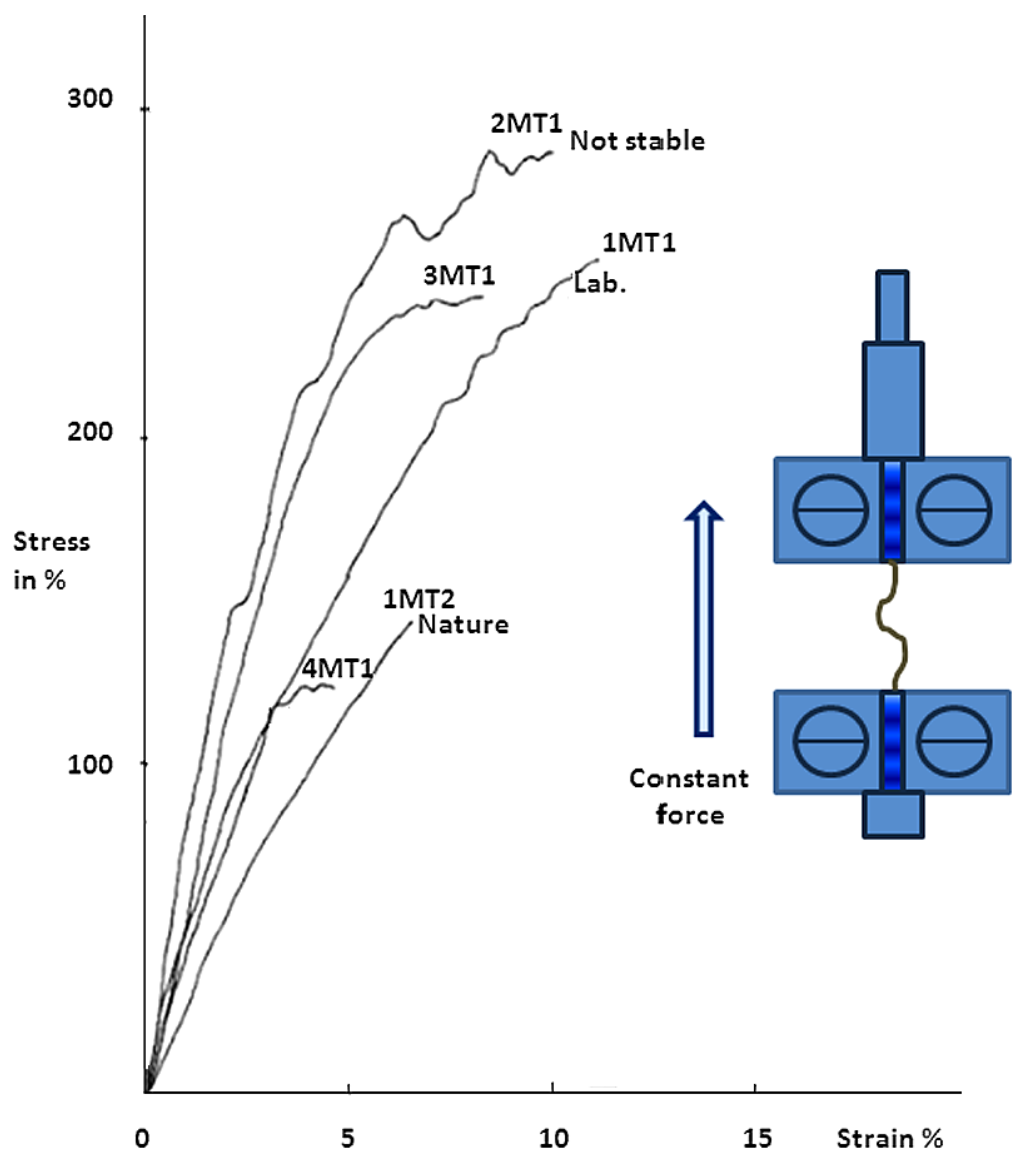

Fig. 6. Representative stress-strain curves of some samples. (Colors are visible in the online version of the article; http://dx. doi.org/10.3233/SPE-2011-0495.)

\subsection{FTIR spectra}

The assignment of the amide component bands to different types of secondary structures is a critical step in the interpretation of infrared spectra of proteins. The FTIR spectra of eight spiders silks (numbered 1-8) (Eresus cinnaberrinus (1), Gnaphosidae (2, 3, 4 and 5), Philaeus chrysops ((6) which is belong to Salticidae family), Uroctea durandi (7) and Steatoda paykulliana (8) were analyzed.

The amide group of proteins and polypeptides presents characteristic vibrational modes (amide modes) which are sensitive to protein conformation. Amide I (1700-1600 $\mathrm{cm}^{-1}$ region) is primarily due to the $\mathrm{C}-\mathrm{O}$ stretching vibration, amide II $\left(1600-1480 \mathrm{~cm}^{-1}\right.$ region) to the coupling of the $\mathrm{N}-\mathrm{H}$ inplane bending and $\mathrm{C}-\mathrm{N}$ stretching modes and amide III $\left(1350-1190 \mathrm{~cm}^{-1}\right.$ region) to the $\mathrm{C}-\mathrm{N}$ stretching coupled to the in-plane $\mathrm{N}-\mathrm{H}$ bending mode. Furthermore, vibrations of certain amino-acid side chains have absorption bands on the $1480-1350$ and $1190-700 \mathrm{~cm}^{-1}$ region and may deliver minor contributions to the intensity of characteristic protein amide bands $[3,4,6,11,18,21,25,26]$. The region from 1600 to $1640 \mathrm{~cm}^{-1}$ arises from $\beta$-sheets. The region from 1640 to $1660 \mathrm{~cm}^{-1}$ was included contributions from random coil and $\alpha$-helix structures in the silk fibroin. The remaining part of the amide I region from 1660 to $1690 \mathrm{~cm}^{-1}$ arose mainly from turns. 


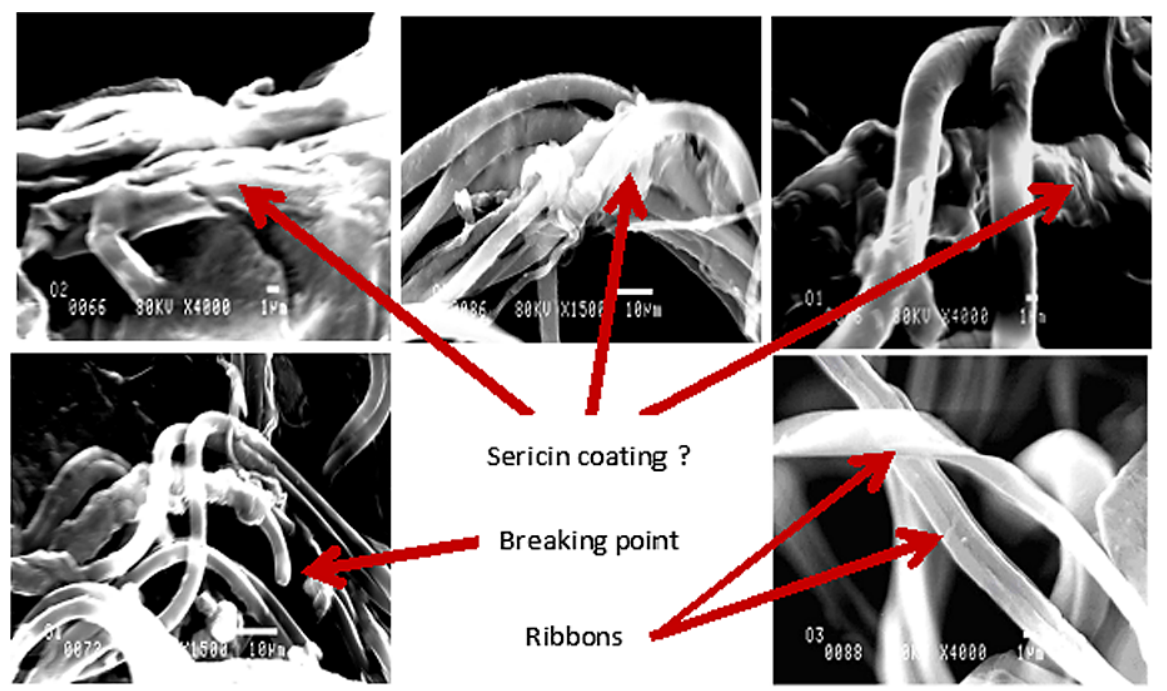

Fig. 7. Different aggregations covering the silk fibers. (Colors are visible in the online version of the article; http://dx.doi.org/ 10.3233/SPE-2011-0495.)

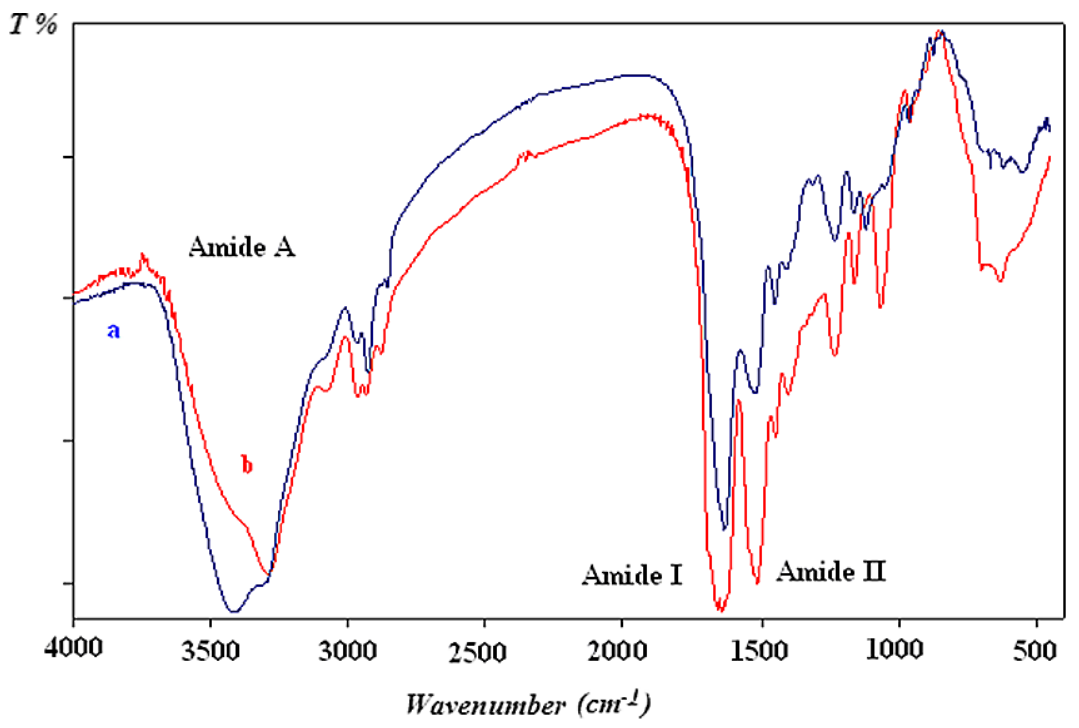

Fig. 8. Infrared spectra of (a) Eresus cinnaberinus (1) and (b) Steatoda paykulliana (8). (Colors are visible in the online version of the article; http://dx.doi.org/10.3233/SPE-2011-0495.)

The infrared spectra in the $4000-400 \mathrm{~cm}^{-1}$ region of Eresus cinnaberrinus (1) and Steatoda paykulliana (8) are shown in Fig. 8 as representative illustrations.

The band at $3413 \mathrm{~cm}^{-1}$ can be assigned, to the $\mathrm{N}-\mathrm{H}$ stretching band (Amide A). There exist considerable shifts in the positions of the bands in the $\mathrm{N}-\mathrm{H}$ stretching band region between different kinds of samples. Variation to lower frequencies is due to an increase in hydrogen bonding of the affected secondary amino functions in samples.

The infrared spectra for the samples Gnaphosidae $(2,4)$, Uroctea durandi (7) and Steatoda paykulliana (8) showed a strong amide I band at $1645 \mathrm{~cm}^{-1}$; this position correlates with a silk I-like or a "ran- 
dom coil" (amorphous) structure in silks and silk-like proteins (polypeptide fragments in a non-ordered (random) conformation).

The infrared spectra of the Eresus cinnaberrinus (1), Gnaphoside $(3,5)$ and Philaeus chrysops $(6)$ showed a strong amide I band at ca $1636 \mathrm{~cm}^{-1}$. The band around $1630 \mathrm{~cm}^{-1}$ was proposed to represent short-segment chains ( $\beta$-strands) connecting helical segments, and not involved in typical $\beta$-sheet structures. Amide I band at $1636 \mathrm{~cm}^{-1}$ for Agelena labyrinitica $1635 \mathrm{~cm}^{-1}$ for Heliophanus flavipes and $1645 \mathrm{~cm}^{-1}$ for Cheirecanthium erraticum was observed.

The bands observed at $1695 \pm 2 \mathrm{~cm}^{-1}$ in the infrared spectra of the samples $(2,6,7$ and 8$)$, can be attributed to antiparallel $(\uparrow \downarrow) \beta$-sheets. This high-frequency amide I component was also observed for poly(L-alanylglycine) and for $\beta$-poly(L-alanine) $[17,28]$.

We observed a band at $1660 \mathrm{~cm}^{-1}$ in the amide I region in addition to the band at $1645 \mathrm{~cm}^{-1}$ in the infrared spectrum of Steatoda paykulliana (8). It is typical of fibrous proteins in a 3-fold polyglycine II or polyproline II conformation (glycine-rich region [43]). The infrared spectra for the all samples indicated an amide II band at ca $1516 \mathrm{~cm}^{-1}$. The band shift was found for the amide II band from 1516 to $1522 \mathrm{~cm}^{-1}$ for Eresus cinnaberrinus (1).

We observed a shoulder near $1260 \mathrm{~cm}^{-1}$ in the amide III region through the infrared spectrum of Uroctea durandi (7). This can be correlated with small contribution from disordered backbone. The band at $640 \mathrm{~cm}^{-1}$ for Uroctea durandi (7) is due to tyrosine ring mode, and the band at $621 \mathrm{~cm}^{-1}$ is due to phenylalanine ring modes [7].

As summary, it can be said that, Eresus cinnaberrinus (1), Philaeus chrysops (6), Uroctea durandi (7), Steatoda paykulliana (8) have rich protein content according to the FTIR assignments.

The detailed IR assignments related with all samples may be obtained from the authors.

\subsection{SAXS results}

The correlation lengths is an important structural parameter and it indicates the inter crystallite distance $\left(l_{\mathrm{c}}\right)$. The crystallite parts in the spider silk filament fibers are shown in Fig. 9.

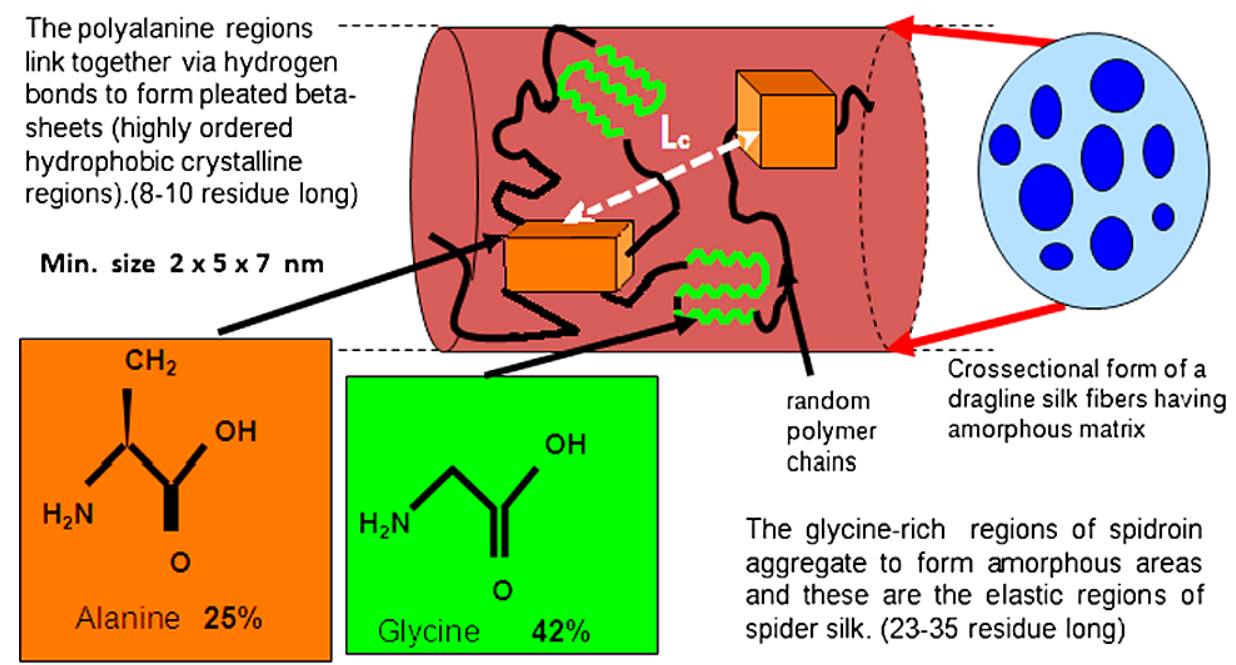

Fig. 9. Alanine and glycine-rich regions indicating crystalline parts of a dragline silk fiber. (Colors are visible in the online version of the article; http://dx.doi.org/10.3233/SPE-2011-0495.) 
Prismatic shapes are simulating alanine crystallites while the zigzag shape is indicating glycine-rich regions [8]. The measured range for the correlation length is 183.7-268.5 ̊. From the SPI sequence, range of the expected correlation length along meridional direction was 13-18 nm. Our results showed the bigger SPI sequence and distance between the $\beta$-sheets. After the more detailed modeling studies, we may find the size of silk fibril segments, too. Expected value is in the range of 400-800 $⿱$. At the end of SAXS measurements, experimental data (circles) had been fitted to a known scattering model (continuous line) (Fig. 6). According to the theoretical model, Eq. (1) [27] is used to calculate scattering intensity $(I)$ as a function of the magnitude of scattering vector $(q)$ :

$$
I=K l_{\mathrm{c}}^{2} /\left[1+\left(l_{\mathrm{c}} q\right)^{2}\right] .
$$

In the equation, $l_{\mathrm{c}}$ is an important structural parameter defined by correlation length indicating the inter crystallite distance in the structure of silk. $K$ is also indicating the measure of the number of nanosized crystallites. So it can be said that, along meridional directions number of nano-aggregations are much more than that of equatorial direction of the silks. In cocoon bunch, correlation lengths are slightly different for the directions. But for dragline samples, along meridional direction $l_{\mathrm{c}}$ is degreasing in recordable rates. These results may be summarized as mechanical strength properties are more powerful along the meridional direction than that of equatorial strength.

\subsection{DLS results}

The widely measured mean size range of nano-structured aggregations in the silk samples is determined as $\sim 3 \mathrm{~nm}$ for our samples. Beside of this mean size (for 13 samples), the minimum and maximum measured mean sizes for two samples are 5.7 and $187 \AA$, respectively (Fig. 7). $5.7 \AA$ (as a small value) may be indicated as a unit cell parameter detected in crystalline structure. $187 \AA$ is in the range of 183.7$268.5 \AA$ which were measured in SWAXS analysis. But in the gel form of the silk samples, crystalline aggregations may be partly solved in the solution and it may cause the absent of bigger aggregations such as in that of SAXS results.

\subsection{Mechanical testing}

Suture (W9940 Ethicon coated polyglactin 910) filaments [9] were also measured to compare strain and stress values with those of silk samples. Strain and stress values of the suture have been measured as 9.28 and $3010.93 \mathrm{~N} / \mathrm{mm}^{2}$, respectively. According to the mechanical testing result, it can be said that, extensibility and tensile strength of the silks can be increased by a good protein diet (flies, larva and several small bugs: feeding period: a week). Strain (and stress values) of the samples related with Eresus cinnaberinus (1MT1, 1MT2 (Lab.)) were increased from $6.73\left(139.02 \mathrm{~N} / \mathrm{mm}^{2}\right)$ to $11.87\left(244.97 \mathrm{~N} / \mathrm{mm}^{2}\right.$ ) under laboratory conditions comparing to natural cases. General comparisons between the selected valuable samples have been showed that the silk filament of Araneus angulatus (2MT1) has biggest strain but homogenous extensibility was not obtained because of the broken of some fibers in the filament. This result can be observed in the samples which have differences in the diameters of dragline used to make the filament. The thin dragline can start to break in the small strain and stress applications.

At the end of our studies, the valuable species were determined as Argiope lobata, Araneus angulatus, Agelena labyrinthica, Uroctea durandi and Eresus cinnaberinus (Table 3). 
Table 3

Important species determined as scientifically valuable in the investigated regions in Turkey

\begin{tabular}{ll}
\hline Valuable species & \multicolumn{1}{c}{ Properties } \\
\hline 1. Argiope lobata (Pallas, 1772) & Yellow color, strong dragline and coccon \\
2. Araneus angulatus (Clerck, 1757) & White color, strong dragline \\
3. Agelena lambyrinthica (Clerck, 1757) & Productive spider, strong dragline \\
4. Uroctea durandi (Latreille, 1809) & White color, strong hiding silks, productive spiders \\
5. Eresus cinnaberinus (Oliver, 1789) & Pink color, strong and glue coated hiding silks, productive spiders \\
\hline
\end{tabular}

\section{Conclusion}

Interdisciplinary studies have been performed for the first time on a variety of spider silks from Turkey. Beside of the structural information related with spider silk contents, which spider species are valuable and have long life in the laboratory conditions were also determined. Hierarchical structure and superior properties of natural fibers can give considerably varying responses depending on spider species their feeding, feeling, natural environment and conditions, etc. It was found that the species of Eresus cinnaberinus is very eager to weave its silk and it has long life in the laboratory type life cabin. In the light of this information, our investigations will be focused on this species. On the other hand, as known as high flux synchrotron radiation should be used to deeply investigate the spider silk structure (especially in the wet form of the silks) by using XRD and SAXS methods. Our future studies will be also on the silks weaved by the determined species using SR.

\section{Acknowledgements}

We are grateful to Prof. Peter Lagner and Prof. Olgun Güven for their supports about SAXS and mechanical testing measurements. This study was supported by TUBITAK (Project: TBAG-107T017) and Hacettepe University Scientific Research Unit (Project: 06A602012).

\section{References}

[1] A. Bram, C.I. Brändén, C. Craigi, I. Snigireva and C. Riekel, J. Appl. Cryst. 30 (1997), 390-392.

[2] E. Bramanti, D. Catalano, C. Forte, M. Giovanneschi, M. Masetti and C.A. Veracini, Spectrochimica Acta Part A 62 (2005), 105-111.

[3] S.W. Cai and B.R. Singh, Biophys. Chem. 80 (1999), 7-20.

[4] S.W. Cai and B.R. Singh, Biochemistry 43 (2004), 2541-2549.

[5] S. Chen, S. Gido, R. Valluzzi and D. Kaplan, available at: http://flux.aps.org/meetings/YR01/MAR01/abs/S1560087.html.

[6] E.A. Cooper and K. Knutson, Fourier transform infrared spectroscopy investigations of protein structure, in: Physical Methods to Characterize Pharmaceutical Proteins, Plenum, New York, 1995, pp. 101-143.

[7] J. Dong, Z.L. Wan, Y.C. Chu, S.N. Nakagawa, P.G. Katsoyannis, M.A. Weiss and P.R. Carey, J. Am. Chem. Soc. 123(32) (2001), 7919-7920.

[8] N. Du, X.Y. Liu, J. Narayanan, L. Li, M.L. Min Lim and D. Li, Biophys. J. 91 (2006), 4528-4535.

[9] Ethicon Products, available at: www.ethiconproducts.co.uk.

[10] S. Fossey, D. Kaplan and E.J.E. Mark, Silk protein, in: Polymer Data Handbook, Oxford Univ. Press, New York, 1999.

[11] F. Fu, D.B. Deoliveira, W.R. Trumble, H.K. Sarkar and B.R. Singh, Appl. Spectrosc. 48 (1994), 1432-1441.

[12] J. Gatesy, C.Y. Hayashi, D. Motriuk, J. Woods and R.V. Lewis, Science 291 (2001), 2603-2605.

[13] A. Glisovic, J. Thieme, P. Guttmann and T. Salditt, Int. J. Biol. Macromol. 40 (2007), 87-95.

[14] M.J. Gosline, A.P. Guerette, S.C. Ortlepp and N.K. Savage, J. Exp. Biol. 202 (1999), 3295-3303.

[15] S. Heimer and W. Nentwig, Sipinnen Mitteleuropas. Ein Bestimmungsbuch, Berlin, 1991.

[16] M.B. Hinman and R.V. Lewis, J. Biol. Chem. 267 (1992), 19320-19324. 
[17] S. Krimm, Biopolymers 22 (1983), 217-225.

[18] S. Krimm and J. Bandekar, Adv. Protein Chem. 38 (1986), 181-364.

[19] J. Kummerlen, J.D. Van Beek, F. Vollrath and B.H. Meier, Macromolecules 29 (1996), 2920-2928.

[20] J. Laugier and B. Bernard, CELREF Grenoble (INPG), available at: http://www.inpg.fr/LMGP.

[21] D.C. Lee and D. Chapman, Methods Mol. Biol. 22 (1994), 183-202.

[22] G. Levy, Araneae: Thomisidae, in: Fauna Palaestina, Arachnida II, Israel Academy of Sciences and Humanities, Jerusalem, 1985.

[23] G.H. Locket and A.F. Millidge, British Spiders, Vol. 1, The Ray Society, London, 1951.

[24] G.H. Locket and A.F. Millidge, British Spiders, Vol. 2, The Ray Society, London, 1953.

[25] A.V. Mikhonin and S.A. Asher, J. Am. Chem. Soc. 128 (2006), 13789-13795.

[26] A.V. Mikhonin, S.V. Bykov, N.S. Myshakina and S.A. Asher, J. Phys. Chem. B110 (2006), 1928-1943.

[27] L.D. Miller, S. Putthanarat, R.K. Eby and W.W. Adams, Int. J. Biol. Macromol. 24 (1999), 159-165.

[28] W.H. Moore and S. Krimm, Biopolymers 15 (1976), 2465-2483.

[29] A.D. Parkhe, S.K. Seeley, K. Gardner, L. Thompson and R.V. Lewis, J. Mol. Recognit. 10 (1997), 1-6.

[30] D. Porter, F. Vollrath and Z. Shao, Eur. Phys. J. E 16 (2005), 199-206.

[31] P. Poza, J. Perez-Rigueiro, M. Elices and J. Lorca, Eng. Fract. Mech. 69 (2002), 1035-1048.

[32] C. Riekel and F. Vollrath, Int. J. Biol. Macromol. 29(3) (2001), 203-210.

[33] F. Robert, M. Zurovec and F. Sehnal, J. Biol. Chem. 278(37) (2003), 35255-35264.

[34] M.J. Roberts and F. Collins, Guide Spiders of Britain and Northern Europe, London, 1995.

[35] M.E. Rousseau, T. Lefèvre, L. Beaulieu, T. Asakura and M. Pezolet, Biomacromolecules 5 (2004), 2247-2257.

[36] A.H. Simmons, C.A. Michal and L.W. Jelinski, Science 271 (1996), 84-87.

[37] A.H. Simmons, E. Ray and L.W. Jelinski, Macromolecules 27 (1994), 5235-5237.

[38] J. Sirichaisit, V.L. Brookes, R.J. Young and F. Vollrath, Biomacromolecules 4 (2003), 387-394.

[39] B.O. Swanson, A. Blackledge, A.J. Beltran and C.Y. Hayashi, Appl. Phys. A 82 (2006), 213-218.

[40] J.D. Van Beek, S. Hess, F. Vollrath and B.H. Meier, Proc. Natl. Acad. Sci. USA 99 (2002), 10266-10271.

[41] F. Vollrath and D. Knight, Nature 410 (2001), 541-548.

[42] J.O. Warwicker, Acta Cryst. 7 (1954), 565-573.

[43] D. Wilson, R. Valluzzi and D. Kaplan, Biophys. J. 78 (2000), 2690-2701.

[44] M. Xu and R.V. Lewis, Proc. National Academy of Sciences USA 87 (1990), 7120-7124.

[45] Z. Yang, D.T. Grubb and L.W. Jelinski, Macromolecules 30 (1997), 8254-8262. 


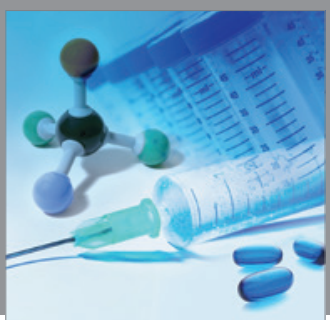

International Journal of

Medicinal Chemistry

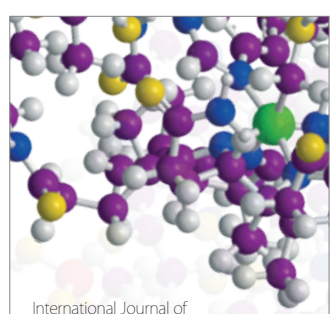

Carbohydrate Chemistry

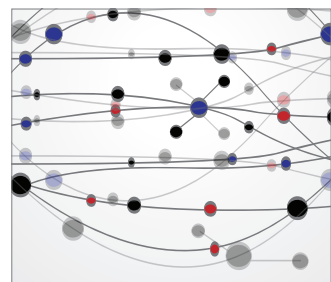

The Scientific World Journal
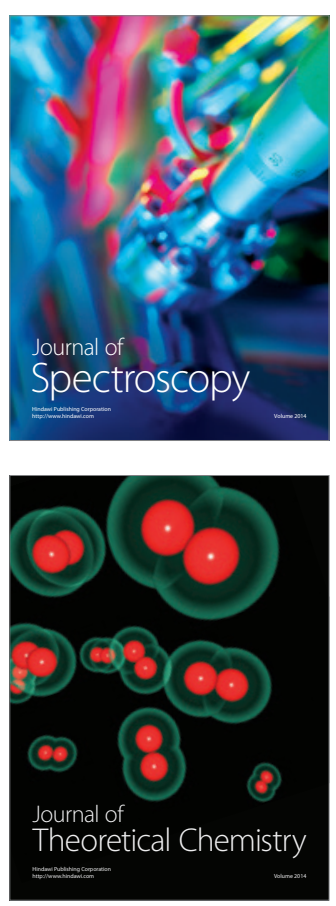
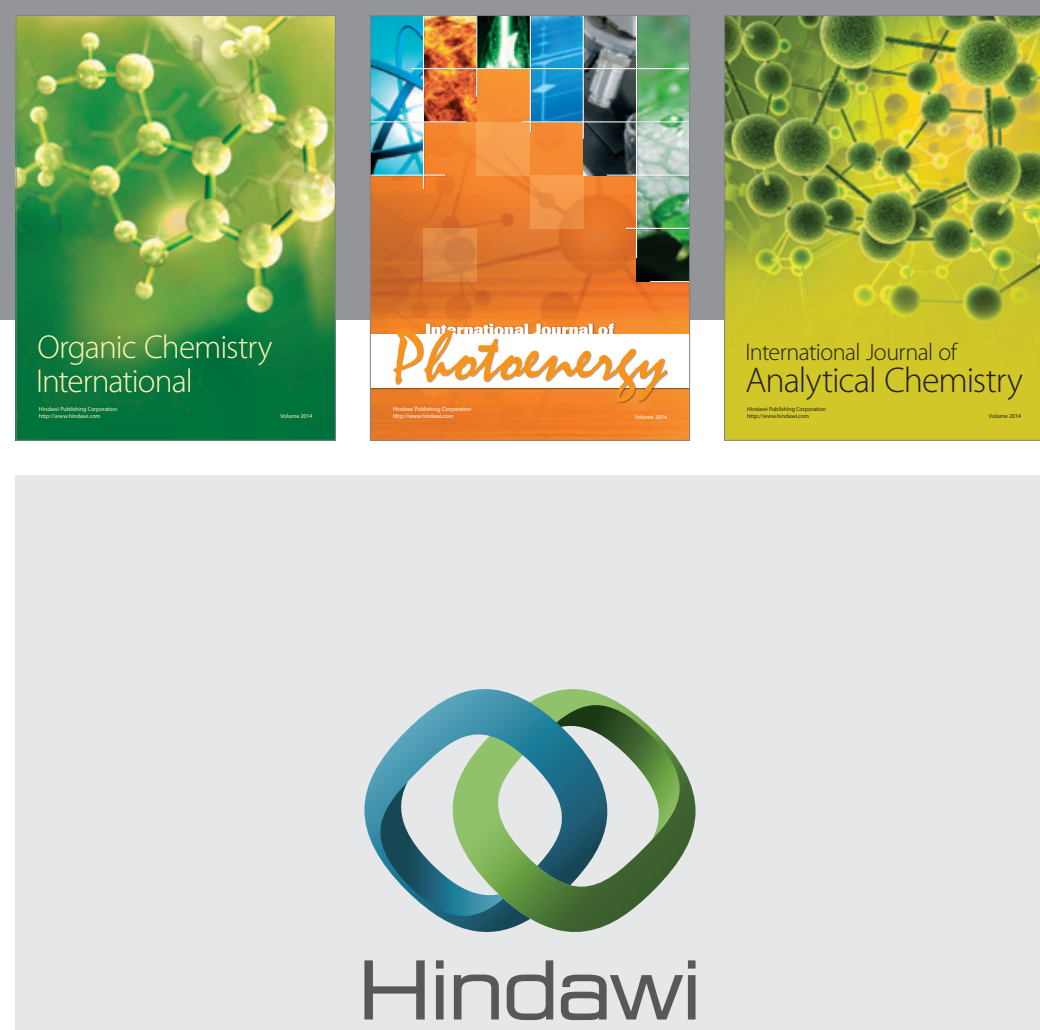

Submit your manuscripts at

http://www.hindawi.com
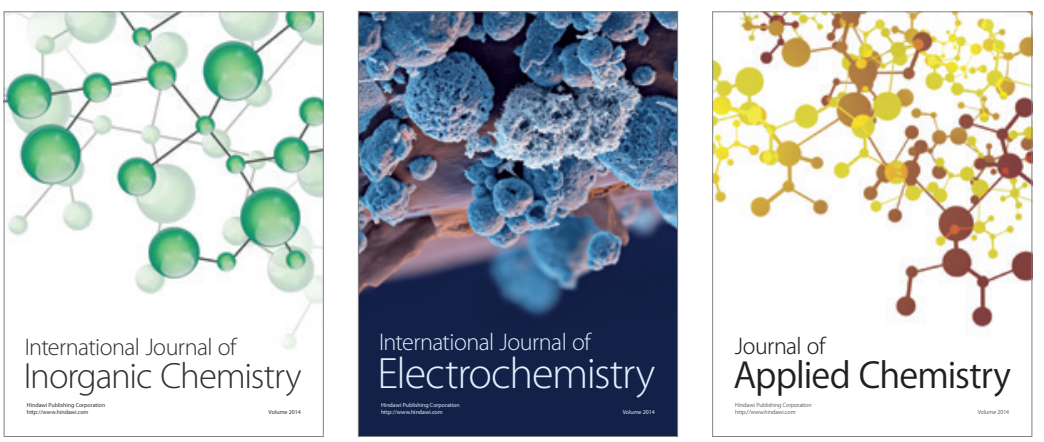

Journal of

Applied Chemistry
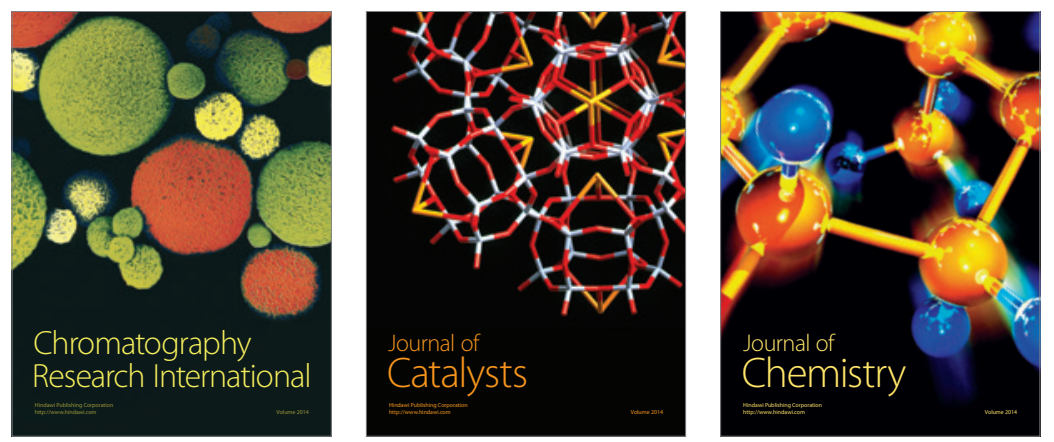
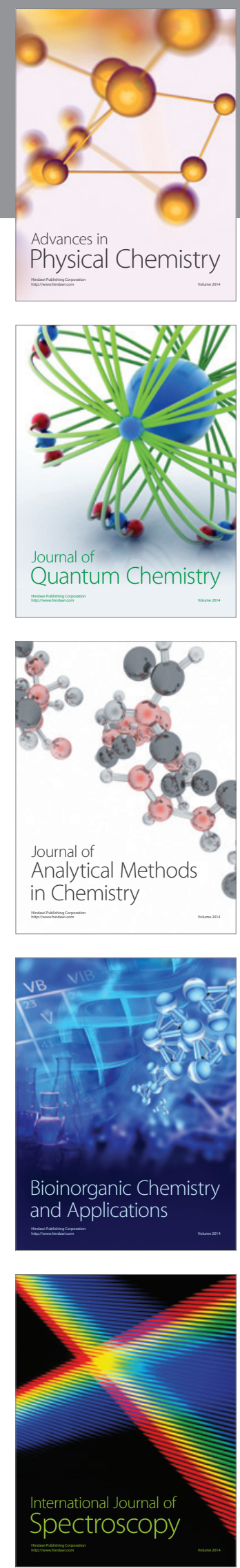